\title{
Spirometric Studies in Women of Two Population Samples from Rural and Urban Area in Punjab-Effect of Biomass on Lungs
}

\author{
Dr. Iqbal Singh(MD) ${ }^{1}$ Dr. Sarabjitkaur(MDS $)^{2,}$ Dr. Avnishkumar(MD) ${ }^{3}$ \\ ${ }^{1}$ Assistant Professor Deptt. of Physiology Govt. Medical College Patiala Punjab \\ ${ }^{2}$ Assistant Professor Deptt. of Prosthodontics Govt. Dental College Patiala Punjab \\ ${ }^{3}$ Professor Depttof Physiology Govt. Medical College Patiala Punjab
}

\begin{abstract}
Inhalation of BiomassFumes over a long time leads to proliferation and fibrotic changes in Lungs. Early recognition of this damage provide, an important clue to insure good health. Spirometry is an invaluable screening test to identify patient with air flow obstruction. The study has been conducted as 100 Rural and 100 Urban Punjabi females using Biomass fuel and LPG respectively between 20-50 years of age. The ventilatory tests like PEFR, FEV measured by computerized spirometer (Med-Spiror) showeda highly significant decline in Rural women, While in rest of the parameters there is statistically non-significant decrease in rural women. The cause of decrease in the flow volume in the rural women using Bio-mass fuel is due to respirable suspended Particulate matter like $\mathrm{So}_{2}, \mathrm{No}_{2}, \mathrm{Co}_{2}, \mathrm{CO}$ etc. Which lead to decreased lung function and increased prevalence of chronic bronchitis and COPD. The cause of better preserved lung function in urban women is due to use of other fuels for cooking i.e.,LPG gas and well ventilated homes and because of non exposure to indoor pollution as in case of using biomass fuels. So chronic Exposure to biomass smoke is associated with chronic bronchitis and reduced lung function in rural women.
\end{abstract}

Keywords:Biomass fuel , PEFR, FEV ${ }_{1}$ Rural women, COPD, IndoorAir Pollution

\section{Introduction}

Spirometry is vital in Screening, diagnosing and monitoring of patients in clinical respiratory medicine. The Interpretation of these results depends on comparison with reference values derived from a pool of normal healthy Population. PFT parameters were mainly influenced by body height and weight in both sex ${ }^{1}$. PFT's are affected by factors including diet, obesity, air pollution and physical activity level. In the last two decades, rapid economic growth and development worldwide has resulted in an improvement in peoples nutritional status. At the same time, airpollution levels have increased and peoples physical activity levels have decreased ${ }^{2}$. Pulmonary function tests (PFT's) are widely used to measure the performance of lungs during physiological and pathological conditions. PFT's determine lung capability of holding air, amount of air moving in and out and how well Lungs take in Oxygen and remove carbon-dioxide from blood. These tests also measure pathology in Lungs if any present and hence used as diagnostic tests for lung disease. Spirometry being the most commonly performed Lung function test is considered as first choice in diagnosis of lung pathology. It measures amount of air that can be moved in and out of one's lungs ${ }^{3}$.

The majority of indoor air pollutions e.g., the respirable suspended particulate air matter, sulpher dioxide, carbon dioxide, carbon monoxide and Nitrogen dioxide for all seasons have showed that respiratory problems for women and children in urban slums occur mostly in winter ${ }^{4}$.

There is increasing evidence for a possible association between chronic obstructive pulmonary disease (COPD) and the use of biomass fuels for cooking and heating in developing countries. Indoor pollutants from biomass fuels may be an important risk factor for COPD in rural south china ${ }^{5,10}$.Indoor pollution exposures were associated with the Presence of acute respiratory symptoms and mild lung functions in a rural and an urban area ${ }^{6}$. Biomass (organic) fuels cause exposed to biomass fumes are more likely to suffer from chronic bronchitis (CB) and COPD than urban women, although from chronic prevalence of smoking is high among the later groups ${ }^{7}$.

Prevalence of asthma was more in cases having positive family history of atopy and in those staying in poorly ventilated thatched houses. No Significant difference was found in asthmaprevalence between urban and rural population ${ }^{8}$. It has been suggested that poor nutritional status lead to poor growth of muscle and development of lungs and consequently decreased lung function ${ }^{9}$.

Prevalence of chronic bronchitis was significantly associated with heating source, age, area of residence and lower socioeconomic status ${ }^{11}$. Height showed the greatest effect on the predicted value of $\mathrm{FEV}_{1}$ and FVC in males and females. Height has the greatest effect on the predicted value of FEV 1 $\%$ in females where as weight has the least effect ${ }^{12}$. 


\section{Material and Methods}

This study was conducted among 100 rural females using organic fuel (biomass) as sole fuel in their kitchen as cases and 100 urban funds as controls not using the biomass fuel but using natural gas i.e. LPG in and around Patiala, Punjab between 20 -50 year of age.

Judged to be healthy or the criterion of no exertionaldysponea/general dability,h/o current/ past cardio respiratory disorder or frequent cold, obvious sign of malnutrition, no obesity, h/o smoking and a detailed physical examination was carried out and Hbconcentration was done. The lung function testwere suggested by Gandevia and Hugh Jones and cotes. the procedures were quite simple from patients. Point of view only two maneouver were required to accumulate all test data i.e. a forced vital capacity and maximum voluntary ventilation. All gas volumes are corrected to B.T.P.S ( body temperature ambient pressure and Saturated with water Vapour) automatically by the instrument. Pulmonary function terms were carried out in standing position, height was measured in centimeters, weight was measured in Kilograms, body surface area was read from "Nomogram"Dobous and Dobous.

In the Procedure of lung function a nose clip was attached to the subject and a clean mouth piece was inserted into the breathing tube two maneouverwere performed.

1) Forced vital capacity test:- subjects wereinstructed to take maximum inspiration and then place mouth piece firmly in mouth and preformed, maximum expiration.

2) Maximum voluntary ventilation testprocedures:- After rest of five minutes the subject was asked to breathe as rapidly and deep as possible in and out from the mouth piece. MVV test was run for 12 seconds. Results were taken on the built in printer containing all the patients information and calculated values of all the 14 parameters.

\section{Statistical Analysis}

The various statistical consideration used were mean, standard deviation, correlation Coefficient and regression equation was evaluated by constructing ANOVA table.

\section{Results}

Anthropometric parameters in cases and controls are shown in Table 1 showing mean standard deviation ' $t$ ' value ' $\mathrm{P}$ ' and significance. The value of PEFR, $\mathrm{FEV}_{1}$ shows statistical significant difference between cases and controls. PEFR Table 2.Shows Mean 'SD'and ' $t$ ' value significance in the cases and controls and show that it is statistically significant.

$\mathrm{FEV}_{1}$ Table 3.show mean 'SD' and 't' value significance in the cases and control and show that it is statistically significant.

Table 1: Comparison Of Anthropometric Parameters In Cases And Controls Population

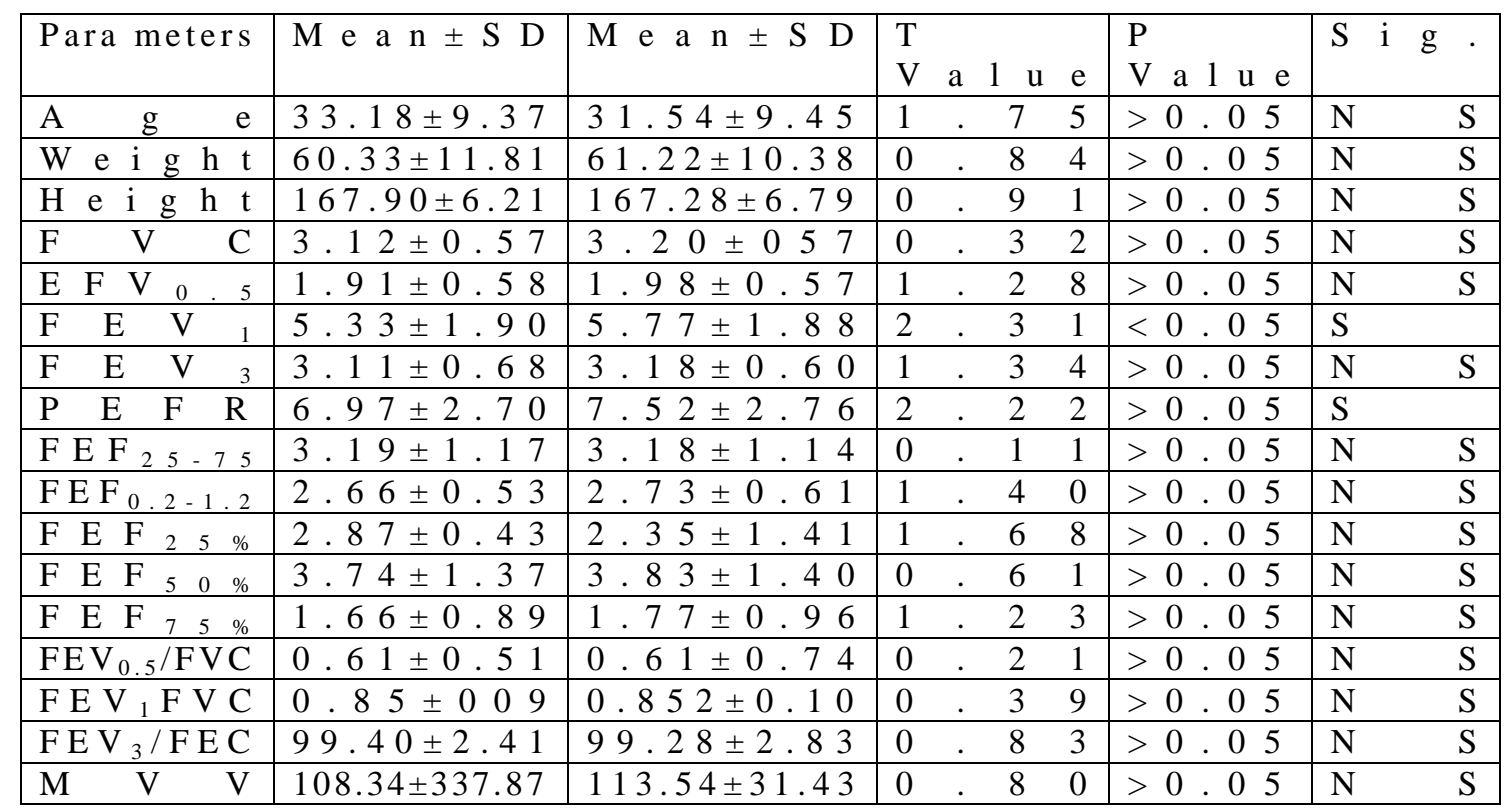

S- Significant

NS- Non Significant 
Spirometric Studies In Women of Two Population Samples From Rural And Urban Area In...

Table -2 Mean \pm SD, $t$ value and significance of PEFR

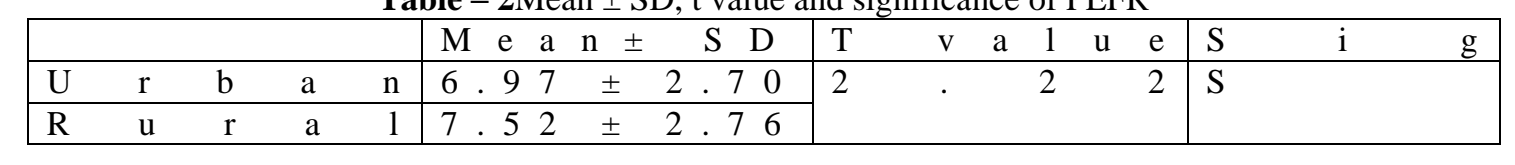

Table-3 Mean \pm SD, $t$ value and significance of PEFR

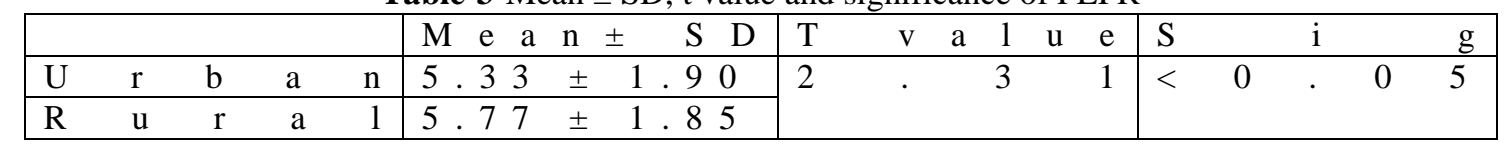

\section{Discussion}

This study was done with an aim to collect more data on women using biomass fuels in rural population and LPG using urban female population as there was marked difference between urban and rural areas and to bridge the gaps in our knowledge.

In this study, was found that rural women (20-50 yrs of age) were of low socio economic status living in small congested houses using solely the biomass (organic) fuels for cooking or heating purposes for 6-7 hours daily and urban women were using fuels other than the biomass fuels i.e. LPG gas and were of good socio economic status and living in non congested," well ventilated houses"

This study showed that the women using biomass fuels (case) for the cooking even with a chimney as

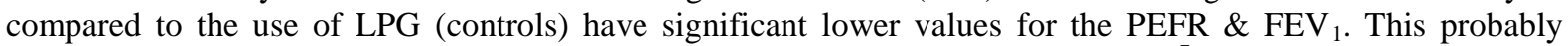
because of indoor particle concentration were higher in houses using biomass flues ${ }^{7}$. It has been observed that the Peak indoor particulate matter $\left(\mathrm{PM}_{10}\right.$, Particles with a diameter of $10 \mathrm{~mm}$ or less) often exceeded $2 \mathrm{mg} / \mathrm{m}^{3}$ compared with those cooking with gas. Current use of stove burning (Chula) biomass fuels was associated with increased reporting of phlegm and reduced lung function, levels of $\mathrm{FEV}_{1}$, were lower with higher $\mathrm{PM}_{10}$ concentration. The respirable particulate matter like $\mathrm{No}_{2}, \mathrm{Co}_{2}$, Co were found in high concentrated especially in winters and cause chronic bronchitis and $\mathrm{COPD}^{2,8}$.

\section{Conclusion}

The study of lung function parameters conducted on 100 Rural women using biomass fuels (cases) and 100 urban women using LPG (controls). The cases as of low socio economic status use to dwell in small congested houses and use the biomass fuels because them are cheap and easily available and moreovercannot afford the other means for cooking and controls using LPG for cooking and heating purposes and have better socioeconomic status living in well ventilated houses have showed that decline in the 2 parameter in cases was due to respirable suspended particulate matter in the smoke produced by the biomass fuels and caused the noxious effect of indoor air pollution on the lungs. The cause of better preserved lung function of controls is due to lesser exposure to the respirable suspended particulate matter $\mathrm{Co}_{2}, \mathrm{Co}, \mathrm{No}_{2}, \mathrm{So}_{2}$ etc. and better living standard in well ventilated houses. More phlegm production in women using biomass fuels than LPG using women. Chronic bronchitisand airflow obstruction were increased in women who had been exposed to wood smoke.

Solid fules are a major source of indoor air pollution but in developing countries the short term effects of indoor air pollution are poorly understood compared with other fuel types, coal was associated with a lower health status including negative impacts on exhaled carbon monoxide level, forced vital capacity, life time prevalence of chronic obstruction pulmonary disease and asthma and health care utilization. Decreasing household coal use (solid fuels) increasing are of improved store technology and increasing kitchen ventilation may decrease the short term health effects of indoor air pollution.

\section{Reference}

[1]. Nepal GB, Dass PKL, Bhalia A: Spirometric Evaluation of Pulmonary functions of Medical Students in Nepal, Asian Journal of Medical Sciences 1 Jul.- Sep. 2014/Vol.5/Issue 3.

[2]. Bandyopadhyaya A, Bhatacharjee I, Dalui R, Pal S: Pulmonary function studies of Healthy non smoking male university students of Kolkata, India- Revised, Malays J Med Sci. Mar-May 2013; 20 (2): 200-2.

[3]. Bhatti U, Rani K, Memon MQ: Variation in Lung Volumes and Capacities among young Males in relations to height. J Ayub Med Collabottabad 2014; 26 (2): 200-2.

[4]. Kulshrestha P, Khare M, Seeta Raman P: Indoor air quality assessment in and aournd urban slums of Delhi city, India Indoor Air 2008; 18:488-498.

[5]. LiuS, ZhouY. Wang X, Wang D, Lu J, Zheng J, Zhong N, Ran P: Biomass fuels are the probable risk factor for chronic obstructive Pulmonary disease in rural South China. Thorax 2007; 623:889-897.

[6]. Simoni M, Scognamiglio A, Carrozzi L, BaldacciS, Angiro A, Pistelli F, Pede FD, Viegi G: Indoor Exposure and acute respiratory effects in two general population samples from a rural and urban areas in Italy. Journal of Exposure Analysis and Enviornmental Epidemiology (2004) $14, \mathrm{~S}_{144}, \mathrm{~S}_{152}$.

[7]. Kiraz K, Kart L, Demir R, Oymak S, Gumez I, UnaLacak M, Ozesmi M: chronic Pulmonary disease in rural women exposed to biomass fumes. Clin invest Med2003; 26 (5): 243-8. 
[8]. Gaur SN, Gupta K, Rajpal S, Singh AB, Rohtagi A : Prevalence of bronchial Asthma and allergicrhinitis among urbanand rural adult population of Delhi. Indian J Allergy Asthma Immunol 2006; 20 (2) : 90-97.

[9]. Akhter N, Begum N, Begum USN, Akhter D, Habib N, Parveen MH: Lung function and chronic exposure to air pollution. J Dhaka National Med. Coll. Hos. 2012; 18 (02) : 5860.

[10]. Regaldo J, Padilla RP, Sansores R, Ramirez JLP braver M, Pare P, Vedal S : The effect of Biomass Burning on Respiratory symptom and Lung function in Rural Mexican women. American Journal of Respiratory and critical care Medicine, Vol. 174 No. 8 (2006), PP. 901-905

[11]. Goel S. Gupta BP, Kashyap S, Bhardwaj AK: epidemiological aspects of chronic bronchitis in Shimla Hills. India J chest Dis allied Sci2007; $49: 143-147$.

[12]. Nayak PK, SatPathy S, Manjareeka M, Samanta P, Mishra J, Pradhan BB : Normal Spirometric standard, in young adult Indian population. Journal of Basic and clinical physiology and Pharmacology. Volume 26, Issue 4 (March 2015), Pages 321-25. 